New Zealand Journal of Industrial Relations, 17(3): 347-358

\title{
COMMENTARY
}

\section{Accident Compensation and Prevention: a Step Back in Time}

\section{Ian Campbell*}

This paper is concerned with the link between accident compensation and prevention and examines aspects where the Accident Rehabilitation and Compensation Insurance Act 1992 (ARCIA) may affect the overall preventive effort. Particular attention is paid to work-related disease, stress, the exclusion of compensation for work-related mental disease and the effect of the new restrictions that ensue from the new definition of "accident." The new provisions for experience rating are examined as well as the possibility that the legislation has opened the way for common law claims where the liability of ACC has been curtailed.

Changes wrought by the Accident Rehabilitation and Compensation Insurance Act 1992 (ARCIA), important though they are, cannot be considered without reference to other recent legislation. Commencing with the Employment Contracts Act 1991, the Government began to introduce a package of reforms which has considerable implications for industrial relations and its allied aspects. The last of the triad was the Health and Safety in Employment Act 1992 (HSEA). It is not possible to consider some aspects of these statutes entirely in isolation, and this paper will focus on the changes in accident compensation that have received less public attention than have other aspects and which, at the same time, are closely related to prevention. The most obvious connection between the ARCIA and the HSEA is the emphasis that Government has laid on the incentive that is being introduced in the form of experience rating. This incentive rests on the assumption that employers will move to eliminate or reduce injuries and disease that attract compensation thus avoiding the possibility of having to pay a penalty or, on the other hand, increase any rebate that may be received under the scheme. What then are some of the key changes? 


\title{
The origins of change
}

These are to be found in the paradoxically named white paper, Accident Compensation: A Fairer Scheme, which clearly foreshadows the intention to reduce the cost of accident compensation in a number of ways. This has been accomplished by abolishing some benefits, transferring the burden of employees' non-work injuries from employers to employees themselves and other restrictive measures limiting entitlement to compensation. At the same time much has been made of a new experience rating system which is being introduced.

The ARCIA sets out several new definitions, a few of which substantially change existing practice and compensation entitlements. Initially it is perhaps useful to recall that it has been well established that in the absence of a specific definition of a word or phrase in any Act or regulation, that word or phrase should be interpreted in its ordinary meaning as set out in any standard dictionary and as Davison CJ reminded us in Wallbutton v ACC [1983] NZACR 629 at 632: "... one must look to the ordinary interpretation of that word to see what is encompassed within the meaning." Thus unless there is a desire on the part of the legislators to restrict the meaning of a particular word in any way there is no need for a specific definition in any statute. Another point to be considered is s5(j) of the Acts Interpretation Act 1924 which provides:

Every Act ... shall be deemed remedial ... and shall receive such fair, large, and liberal construction and interpretation as will best ensure the attainment of the object of the Act ...

\section{As Lord Wright stated in Craig v Dover Navigation Co Ltd [1939] 4 All ER 243 at p.199:}

\begin{abstract}
It has been established by various decisions of this House that the Workmen's Compensation Act is a remedial measure intended to give rights beyond what the common law gave, and that it is a practical measure expressed in non-technical language, to be construed according to the ordinary sense of mankind.
\end{abstract}

Clearly such a view equally applies to Workers' and Accident Compensation Acts. However the Government in introducing a definition of "accident" has rejected the long standing interpretation of that word as applied to the succession of Workers' Compensation Acts and the Accident Compensation Acts of 1972 and 1982. As the White Paper explained:

\begin{abstract}
In the present legislation there is no definition of either personal injury or accident. As a result, the boundaries of the scheme have been extended over the years to cover situations which most people would have difficulty in reconciling with the common view of what an accident is. This, in turn, has led to cost increases. (Birch, 1991: 31)
\end{abstract}

There is no mention of the fact that most people would have difficulty with the interpretation of "accident." An appreciation of what Government had in mind may possibly be gained from an examination of cases reported in recent Law Reports which would probably be excluded by the changes brought in by the ARCIA. For example subparagraph (a) of the definition of "accident" in s3 of the Act, makes it clear that the intention was to exclude any event or series of events that do not involve "the application of a force or resistance external to the human body," a provision that has caused considerable concern. Furthermore, at this stage, there is considerable 
uncertainty as to its ultimate effect, though ACC has issued guidelines in newsletters.

One can well ask by what criteria the Government came to the conclusion that such claims should not be regarded as arising from personal injury by accident. Our law is a dynamic body of knowledge and practice and does not remain static. From time to time the Courts have developed new interpretations or extensions of old ones, as the Courts recognise changing community values and situations. Indeed it could be said that such moves are often too tardy. The incredible decision of Lord Arbinger CB in Priestly $v$ Fowler [1837] $3 \mathrm{M} \&$ W 1 which gave rise to the doctrine of common employment, is a case in point. Though subsequent decisions put a dent in that principle the doctrine was not finally put to rest until the passing of the Law Reform Act 1936. In commenting on the rationale of Lord Arbinger, Lord Wright said many years later in Radcliffe $v$ Ribble Motor Services Ltd [1939] 1 All ER 637 at 651: "[t]hese instances seem to show personal apprehension rather than any principle."

Traditionally administrators prefer issues to be clear-cut but unless there is some degree of discretion allowed to the ultimate authority then some injustices will prevail. As Gault J commented in ACC $v E$ [1992] 2 NZLR 426 at 431:

... to interpret the expression narrowly would be to exclude injuries in respect of which compensation has been paid as a matter of course in the past, such as back injuries sustained in the course of normal lifting work or muscle injuries sustained in sport. Cover for such injuries has been commonplace under the workers compensation Acts and has been commonplace under the Accident Compensation Act at least since the decision of Davison CJ in Wallbutton v ACC [1983] NZACR 629 which followed the House of Lords in Jones v Secretary of State for Social Services.

Nevertheless, over time there have been frequent references to the fact that in the Accident Compensation Act and its predecessors, the Workers' Compensation Acts, there has been no definition of "accident." The British Workmen's Compensation Act 1897 first used the words "personal injury by accident." New Zealand followed in the Workers' Compensation for Accidents Act 1900 . As may be expected, in those early days doubts arose as to how those words should be interpreted. A group of three cases was reported together in [1900] 1 QB 481 . Hensey $v$ White, Lloyd $v$ Sugg \& Co and Walker $v$ Lilleshall Coal Co Ltd. The first case concerned a worker who collapsed and died shortly after endeavouring to turn a stubborn wheel. The second case involved a worker suffering from gout of the hand whose hand was struck by a fellow worker when holding the object being hammered, while the third case concerned a worker who was suffering from a blistered hand but whose foreman insisted on his carrying on to finish a job. His hand was poisoned through contact with oil and red lead. Only Lloyd was awarded compensation as the judge said: "[a]nyone might have a weak hand. Was it to be said that in such a case as this only those with cast iron hands came within the Act."

While it is difficult to follow the reasoning of the appeal judges in the first and third cases, the matter was soon put beyond dispute by a decision of the House of Lords - Fenton $v$ Thorley \& Co Ltd [1903] AC 443. In that case a worker suffered a rupture. As Lord Macnaughton explained at p.448: 
Now the expression "injury by accident" seems to me to be a compound expression. The words "by accident" are introduced parenthetically as it were to qualify the word "injury," confining it to a certain class of injuries, and excluding other classes, as, for instance, injuries by disease or injuries self-inflicted by design. ... I come, therefore, to the conclusion that the expression "accident" is used in the popular and ordinary sense of the word as denoting an unlooked-for mishap or an untoward event which is not expected or designed.

\section{Deciding the boundaries of the scheme}

Initially it is the function of ACC to determine entitlement to compensation, with these decisions being subject to appeal. However no administrative body is infallible and an example of how a determination may be made in a narrow way is well illustrated in decisions concerning compensation for work-related disease, admittedly not an easy topic. In Lynch $v$ Attorney-General [1959] NZLR 445, a case under the Workers' Compensation Act 1956, the question was whether the phrase "due to the nature of any employment" should be interpreted as meaning due to the nature of that industry in general or the particular worker's employment. Archer $\mathrm{J}$ held that it was unnecessary to prove that the dermatitis the plaintiff had developed was a recognised and inherent risk of the operation of mining, but rather of the plaintiff's own employment.

In its earlier deliberations ACC has taken the rather narrow view, such as one case, Decision No 50 (1977) 1 NZAR 295, where compensation was denied to a cleaner who contracted dermatitis and sought to establish that it was caused by the cleansing materials that she was using. It would seem that the Appeal Authority also took the narrow approach holding that no special risk of dermatitis had been proved as the "... ordinary duties of a cleaner did not expose her to a special risk of dermatitis," even though the problems of detergents are well known.

However in a more recent decision of the Accident Compensation Appeal Authority, $R e$ Fyfe: Decision No 29/87 (1987) 6 NZAR 317, the following summary appears in the headnote:

Prior to 1982 the Corporation's policy was based on interpreting the corresponding provision of the 1975 (sic) Act so as to require a claimant to show that the general class of work in which the claimant was engaged had by its nature a recognised tendency to cause the disease complained of. Thereafter, however, the test was widened by allowing compensation also when there was a causal connection between the particular work and the disease - an approach based on Lynch v Attorney-General [1959] NZLR 455 and Connair Pty Ltd v Fredericksen (1979) 53 ALJR 505.

Interestingly, Blair J, the first Accident Compensation Appeal Authority, in commenting on Lynch's case, stated "[i]t may be considered, however, that he expressed the law too widely." (Blair, 1983: 88) The reality is, however, that whether or not the plaintiff's disease was a recognised hazard of the occupation in general or just due to the particular employment, the disease is equally work-related. The decision taken by ACC to use the narrow interpretation throws into question the contention expressed in the White Paper concerning the alleged extension of the boundaries of the scheme and whether ACC has exercised "such fair, large, and 
liberal construction and interpretation as will best ensure the attainment of the object of the Act" in accordance with the Acts Interpretation Act 1924. Presumably Government has, to a considerable extent, relied on advice received from ACC, and ACC in its turn cannot but be influenced by comments from Government circles and elsewhere on the alleged excessive cost of Accident Compensation.

The words of Lord Diplock in Jones $v$ The Secretary of Social Services [1972] AC 944 concerning the British Social Security legislation at p.1005 are of more than passing interest:

To find out the meaning of particular provisions in social legislation of this character calls, in the first instance, for a purposive approach to the Act as a whole to ascertain the social ends it was intended to achieve and the practical means by which it was expected to achieve them. Meticulous linguistic analysis of words and phrases used in different context in particular sections of the Act should be subordinate to this purposive approach.

In ACC v Mitchell [1992] 2 NZLR 436 at 438, Richardson J made a pertinent comment:

... a generous unniggardly interpretation of personal injury accident is in keeping with the policy underlying the Accident Compensation Act of providing comprehensive cover for all those suffering personal injury by accident in New Zealand wherever, whenever and however occurring. And to do so in place of common law remedies. Certainly if the expression is fairly capable of covering all accidental injuries whether or not precipitated by an external triggering incident, that interpretation would better reflect the philosophy underlying this major social legislation.

One could well query whether with the passing of ARCIA the original philosophy has been abandoned, along with the liberal interpretations made by a succession of judges over the years. It is possible that this case and $E$ 's case quoted earlier were ones that the Government considered went beyond the popular concept of injury by accident. But one cannot overlook the cogent reasons adopted by the courts in these decisions. It is strongly suggested that they deserve more consideration than the views of administrators.

The new definition of "accident" has introduced a great deal of uncertainty which ACC has attempted to allay with the issue of extensive newsletters. It is submitted that the new lines which now have to be drawn can result in distinctions equally as confusing as those commented on in the White Paper quoted above.

\section{Disease or injury}

A number of cases have been concerned with injuries that were contracted over time. In Fife Coal Co Ltd v Young [1940] AC 479, a worker suffered some loss of power of dorsiflexion of the right foot. Compensation was awarded as he was able to point to a particular change on a particular day. Injuries that gradually occurred were frequently ruled out as they were not then covered by the disease provisions of the Act. Differentiating disease from injury would seem to be only significant in compensation issues, as occupational health and safety policy, however implemented, seeks to eliminate or reduce both disease and injury. Though the importance of 


\section{Ian Campbell}

this distinction lies largely in matters of compensation, preventive issues may also be affected.

With good reason, some writers have maintained that the distinction drawn between "injury" and "disease", though superficially a logical one, is in many respects an artificial one. Brooks in a detailed examination of the development of judicial interpretation of the concepts of injury and disease in Australia comments: "the resultant obscurity and inaccessibility of these concepts to non-lawyers will be painfully apparent." (Brooks, 1987: 40) Here, as Stapleton maintains, the legal and medical professions seem to differ, noting that: "... the demarcation lines between these classes are artificial from a medical point of view but for various reasons they provide workable classifications for legal analysis". (Stapleton, 1986: 40)

Later Stapleton, after outlining compensation problems with conditions that gradually develop over a period, and the tendency to exclude pathogenic attacks as being due to a "process," comments: "[t]he conceptual irrationality of the distinction is now generally accepted." (p.51) She also mentions that "[m]edical usage itself makes no sharp distinction between injury by accident and disease." (p.50) Ferguson comments: "Acute chemical and physical burns, for example, can be seen as injuries whereas acute and sub-acute internal effects from radiations or inhalation may not." (p.21) He then asks: "is hepatitis B, contracted in a laboratory from accidental needle prick, disease or injury?" (p.21)

There remains considerable room for dispute, which may become crucial when the law attempts to define terms more precisely, as is suggested in the recent White Paper on Accident Compensation. As Boden et al. explain:

Scientific evidence is often essential in the determination of legal causation, but it is not a substitute for it. Both take their origins from common experiences, and both depart from these origins in ways connected with the context in which they are used. In science that context is dominated by objectivity and generality, in law, by the notion of a responsible subject and a singularity and uniqueness of occurrence. ... since law and science have different objectives, some differences in the determination of legal and scientific cause should come as no surprise. (Boden et al., 1988: 1028)

It remains just to note these views which really do not affect the extent of the issues being reviewed.

Though so far New Zealand has not adopted a schedule of occupational diseases, it was considered that the provisions of $s 28$ of the Accident Compensation Act 1982 were sufficiently wide-ranging to cover all those diseases in the World Health Organisation (WHO) schedule, which are almost exclusively occupational diseases rather than work-related ones. Thus when a worker whose work involves exposure to lead contracts lead poisoning there should be no doubt that the disease is "due to the nature of any employment" in the terms of $s 28$ of the Accident Compensation Act 1982. In an official publication the following appears:

While the Accident Compensation Corporation believes that the present legislation gives wider cover than could be given under an exclusive schedule it is at present engaged in preparing a schedule of occupational diseases. The schedule will be adopted for administrative purposes, and will not exclude cover for diseases which are not listed but which qualify in terms of general statutory provision. (Department of Labour,1988: 45) 
However the schedule has not been formalised. A recent International Labour Organisation (ILO) report again considered New Zealand, commenting that the lack of a schedule "leaves the burden of proof ... to the worker (and) is not in accordance with the Convention ...", there being no automatic presumption. It continues:

The Committee therefore once again urges the Government to re-examine this question and to take the necessary measures to bring the national legislation in full conformity with the convention by supplementing the general definition of occupational diseases contained in the Accident Compensation Act by a non-exhaustive list of occupational diseases and corresponding trades, unless it chooses to ratify Convention 121, which provides for, inter alia, the system of "full coverage" in its Article 8(b) and the ratification of which would ipso jure involve the denunciation of Convention 42. (ILO,1992: 167)

However the schedule approach cannot solve the problem of the work-related diseases, for while a schedule could link asbestosis with exposure to asbestos dust, it could not do so with a carcinoma of the lung. The former is an occupational disease, while the latter is regarded as a work-related disease, one which can also arise from a cause unrelated to work. (World Health Organisation, 1985: 9)

It is well known than many injuries come within the heading of "strains and sprains". While many of these would be the result of a resistance, such as lifting or meeting resistance from a stubborn object that the injured person is attempting to shift, some would not. One may well ask why those types of injuries are being singled out for elimination from the scheme. It is difficult to accept that such injuries are ones that the average person would have problems in recognising as a genuine accidental injury. Two questions would seem to arise. What are the types of claims that Government sought to exclude from the operation of the Act? In what way are they so different from other injuries that this course of action was justified? Reference to the White Paper would suggest that the main objective was to cut costs.

\section{Stress}

Continuing its concern with costs, the White Paper then turns to the problem of stress claims, stating:

Stress claims are a major cause of escalating costs in those overseas workers' compensation schemes that compensate for stress. The present scheme does not include stress cover and the Working Party considered that this should not change. Grounds for this conclusion were not only the high costs, but also that stress is the result of a number of interrelated factors.

The Working Party also recommended that physical injury should be present before mental injury is covered. Although this may give an appearance of arbitrariness, this requirement was seen as necessary in order to avoid stress claims entering "through the back door." The Government supports this view. (Birch, 1991: 32)

Thus to avoid the expense of paying stress-related claims all claims for mental disease are excluded unless the mental condition is consequent on physical injury. 
The statement that stress was not then covered by Accident Compensation is incorrect, though admittedly with such claims, it would not be easy to establish the link between the stress and the work. However it would seem that the overstatement in the White Paper was realised, for in the explanatory note to the Bill, after referring to the exclusion of stress cover, it comments: "[t]his gives statutory weight to the current policy." This infers that ACC's nonrecognition of stress claims was without statutory direction. Interestingly, when one claimant sought compensation on the grounds of work-related stress, ACC defended the claim not on the basis that stress was not covered by the Act, but on the absence of proof that the condition was work-related. Re Fyfe: Decision No $29 / 87$ (1987) 6 NZAR 317.

Then there is the drastic move to exclude mental injury unless it results from physical injury. As Lord Macmillan said in Bourhill v Young [1943] AC 92 at p.103:

The crude view that the law should take cognizance only of physical injury resulting from actual impact has been discarded, and it is now well recognised that an action will lie for injury by shock sustained through the medium of the eye or the ear without direct contact. The distinction between mental shock and bodily injury was never a scientific one, for mental shock is presumably in all cases the result of or at least accompanied by, some physical disturbance in the sufferer's system. And a mental shock may have consequences more serious than those resulting from physical impact. But in the case of mental shock there are elements of greater subtlety than in the case of an ordinary physical injury and those elements may give rise to debate as to the precise scope of legal liability.

The ILO has published a number of reports on stress, such as Stress in Industry: causes, effects and prevention by L Levi, OHS Series No 51 (1984). The issue of stress has been aired in the report of a committee considering the problems of firemen involved in the ICI chemical warehouse fire. One of the committee's conclusions was as follows:

We consider that the continuing symptoms displayed by firefighters are the result of long-term and understandable stress caused by their involvement in the fire. Our reasons are:

* a toxicological explanation is wholly inconsistent with what is known of toxicological effect

* the skin symptoms, which are non-specific, could be a result of skin sensitization at the fire, but could also be explained by stress and emotional upset

* the neuropsychological test results may not indicate a statistically significant group response and may themselves measure dysfunction based on stress rather than neurotoxicity

* the GHQ [General Health Questionnaire] results and the uncertainty, anxiety and existence of substantial stressors as a result of the social history of the fire, are all strong pointers to an emotional basis for the symptoms rather than a toxicological one. (ICI Fire Report, 1990: 105)

Thus the exclusion of mental disease is a far reaching one.

It is perhaps well to recall that s2 of the Law Reform Act 1944 was enacted because of an apparent conflict between a decision of the Judicial Committee of the Privy Council and a later decision of the House of Lords. (NZPD 267, 1944: 423) The section 2 provides: 
In any action for injury to the person whether founded in contract or in tort or otherwise, a party shall not be deterred from recovering damages merely because the injury complained of arose wholly or in part from mental or nervous shock.

This is yet another indication of the seriousness of the moves that have been made with the new statute.

The other exclusions specifically made in the new Act are those contained in s7(2): personal injury attributable to either air-conditioning systems or passive smoking. These exclusions are arbitrary and an adequate explanation is elusive. Shortly after the Act was passed, several deaths were reported from Sydney as a result of Legionnaires' Disease. These cases were believed to be due to defective air-conditioning in a shopping mall. Then followed a report, also from Sydney, of a successful damages claim in which passive smoking was implicated.

\section{Experience rating}

The major link between the ARCIA and prevention lies in s104 which provides for experience rating. From the White Paper it could be assumed that Government had accepted that experience rating is regarded as a matter of equity, rather than as an incentive to employers to obey the law. Nevertheless in introducing the Health and Safety in Employment Bill, the Minister stated that "the accident compensation reform of experience rating ... will provide a carrot and stick approach to health and safety in employment." (NZPD 521 (1991 p.6396) Research overseas clearly suggests otherwise. (Campbell, 1989: 3-8)

However, accepting the Government's expectation that their move will provide an incentive for employers to be more active with measures, there is a negative side to the changes. Clearly there is now no incentive for employers to eliminate conditions in their workplaces that are likely to engender stress or cause mental illness; nor are they encouraged to maintain air-conditioning systems or reduce passive smoking.

Two experience rating schemes have been adopted. The first applies to all employers that pay ACC less than $\$ 10,000$ in a year. Employers who are claim-free within the year will get a $15 \%$ no-claims discount. For many employers, being claim-free will be of no significance, for the reality is that with the size and nature of their undertaking a claim will be a very rare event. However, in many of those cases the amount of any rebate will be very small. On the other hand, with the employers approaching the $\$ 10,000$ premium, there will be no balancing penalty with which to pay the rebates, and this will have to be borne in the base rate. For those employers paying $\$ 10,000$ or more, they will either receive a rebate of up to $50 \%$ or pay a penalty of up to $100 \%$. Simply put, if the premiums exceed the claims then a rebate will be paid, and if the claims exceed the premiums than a penalty will be imposed. The resultant figure (rebate or penalty) will be multiplied by an Employer Size Factor. This factor is determined by a table which starts at 0.15 (where the employer's premium is from $\$ 10,000$ to $\$ 10,220$ ) to 0.6 (where the employer's premium is $\$ 1,000,000$ or over).

The Accident Compensation (Accident Experience) Regulations 1992 are gazetted 


\section{Ian Campbell}

seem to have been overlooked in the drafting of those regulations. Subsection (1) requires three factors to be taken into account:

(a) the experience of the employer; and

(b) the frequency of the accidents; and

(c) the financial cost to ACC of those accidents.

Nowhere in the 1992 regulations is any reference made to the frequency rate. Subsection (2) of the 1982 Act requires the experience of the employer to be compared "with the general accident experience of employers ... in the same class." It is impossible for ACC to compare the experience of an employer with the general experience of employers in the same class. The Accident Compensation Employers and Self-employed Persons Levies Order 1991 sets out premiums under 24 Class Numbers. However since ACC abandoned its industry-based classifications and adopted a system based on the Standard Industrial Classifications, then by no stretch of the imagination could it be said that a comparison made within those classes is comparing like with like in accordance with the clear intention of $s 40$. Much more could be written on this aspect of the new legislation. For example, there does not appear to have been any serious consideration given to the suggestion of the Law Commission that there be "a power to impose penalties by reference to observed conditions." (Law Commission, 1988: 39) The "Workwell Program" recently introduced in Ontario also deserves study. It is based on a detailed audit similar to the International Safety Rating System.

\section{Is the way now open for common law claims?}

Finally, there is the extent to which the new Act has reopened the opportunity for an injured person now denied compensation to pursue a claim at common law. Section 14 refers to "personal injury by accident" with respect to cover under the 1972 and 1982 Acts but "personal injury" with respect to the 1992 Act. On the face of it, it would seem clear that a person denied cover by reason of the exclusions introduced by the 1992 Act and who could prove that their injury was caused through the negligence of another party will have the right to sue for damages. Such savings as have been introduced by the new exceptions could well be exceeded by the cost of future common law claims. However, though the answer seems clear that the way has been opened for such actions, this and some other issues must await a determination in the Courts.

\section{Conclusions}

What then has been accomplished by the new ARCI Act? Clearly, rather than simplifying the legislation, many complications have been introduced. Their outcomes must ultimately await legal action. Certainly, compensation entitlements have been reduced, in many cases in a somewhat arbitrary manner. The compensation effects must equally affect future prevention strategies. When the original 1972 Act was under consideration, not a few union officials and others were concerned that, having given up their common law rights, it would only be a matter of time before further ground would be lost. Clearly, their concern was justified and they may now well be considering what will be the next ground to be lost. 


\section{References}

Birch, Hon. W.F. (1991), Accident Compensation: A Fairer Scheme, Wellington, Minister of Labour.

Blair, A.P. (1983), Accident Compensation in New Zealand (2nd Ed), Wellington, Butterworths.

Boden, L.I., Miares, R. \& Ozonoff, D. (1988), Science and Persuasion: Environmental Disease in U.S. Courts, Society, Medicine and the Law, 27: 1019-1029.

Brooks, A. (1987), The concepts of "injury" and "disease" in Workers' Compensation Law - A re-examination in the light of recent reforms, University of New South Wales Law Journal, 10: 39-66.

Campbell, I.B. (1989), Experience Rating for Accident Compensation: A Necessity or Wishful Thinking, Occasional Paper 1989/4, Palmerston North, Massey University.

Department of Labour (1988), International Conventions Ratified in NZ, Wellington, Labour Department.

Ferguson, D. (1986), Occupational Disease and Injury, In Occupational Health and Safety, Douglas, D., Ferguson, D., Harrison, J. and Stevenson, M., Sydney, Australian Medical Association.

The Health Consequences of the ICI Fire: Report to the Minister of Health on the Health of Firefighters in the Fire at the Riverview Store, Mount Wellington, Auckland, 21 December 1984, (1990), Wellington, Health Department.

International Labour Office, Report of the Committee of Experts on the Application of Conventions and Recommendations: Report III (Part 4A) (1992), Geneva, ILO.

Law Commission (1988), Personal Injury: Prevention and Recovery, Report No 4, Wellington, NZLC.

New Zealand Parliamentary Debates, (1944) 267, (1991) 521.

Stapleton, J. (1986), Disease and the Compensation Debate, Oxford, Clarendon.

World Health Organisation (1985), Identification and control of work-related diseases, Report of a WHO Committee, Technical Report Series 714, Geneva, WHO. 
$358 \quad$ Ian Campbell

\section{List of cases}

$A C C \vee E[1992] 2$ NZLR 426.

ACC v Mitchell [1992] 2 NZLR 436.

Bourhill v Young [1942] AC 92.

Connair Pty Ltd v Fredericksen [1979] 53 ALJR 505.

Decision No 29/87 [1987] 6 NZAR 317.

Craig v Dover Navigation Co Ltd [1939] 4 All ER 243.

Decision No 50 [1977] 1 NZAR 295.

Fenton v Thorley \& Co Ltd [1903] AC 443.

Re Fyfe: Decision No 29/87 [1987] 6 NZAR 317.

Hensey $v$ White [1900] 1 QB 481.

Jones v Secretary of State for Social Services [1972] AC 944.

Lloyd v Sugg \& Co [1900] 1 QB 481.

Lynch v Attorney-General [1959] NZLR 445.

Priestly v Fowler [1837] 3 M \& W 1.

Radcliffe v Ribble Motor Services Ltd [1939] 1 All ER 637.

Walker v Lilleshall Coal Co Ltd [1900] 1 QB 481.

Wallbutton v ACC [1983] NZACR 629. 